\title{
Management of Epithelioid Sarcoma of the Inguinal Region with Vascular Invasion
}

\author{
Piyush Gupta $^{1} \cdot$ R. Shankaran ${ }^{2}$
}

Received: 23 January 2017 / Accepted: 10 April 2017 /Published online: 13 April 2017

(C) Association of Surgeons of India 2017

Dear Editor,

We have read with keen interest the article titled, "Management of Epithelioid Sarcoma (ES) of the Inguinal Region with Vascular Invasion" by Amit Mahajan et al. published in the Aug. 2016 issue of the Indian Journal of Surgery.

We congratulate the authors for extensive research and successful surgical outcome in a complex case of ES. We would like to highlight certain aspects in pre op and per operative management which were left to the readers' imagination in the write-up.

To begin with, the exact size and extent of the mass which is an important prognostic indicator needs to be known after imaging and surgical resection [1]. It was told that the lesion encased femoral vessels including the iliac vein, left femoral vein, and the left ureter. The operative procedure involved en bloc resection of the mass with left femoral artery reconstruction and lymph nodes dissection which was successfully carried out, left us quizzing about the status of major veins of the left limb and pelvis after the extensive resection. Primary venous repair alongside the arterial one was an available option with the authors [2].

Piyush Gupta

piyush_gupta18@rediffmail.com

Military Hospital Dinjan, Dinjan, Assam, India

2 Department of Surgery, AFMC, Pune, India
The pathological work-up was extremely meticulous however, the extent of lymph node dissection needed elaboration, since it is pathologically significant.

ES are rare soft tissue tumors, and warrant meticulous pre op work-up, surgical excision, and adjuvant chemotherapy.

Intellectual Contribution of Authors Drafting and Manuscript Revision: Maj (Dr) Piyush Gupta

Supervision: Surg Capt (Dr) R Shankaran

Statistical Analysis: NA

\section{Compliance with Ethical Standards}

Conflicts of Interest The authors declare that they have no conflict of interest.

\section{References}

1. Larsen MB, Bækgaard N (2012) Acceptable results after venous reconstructive surgery following iatrogenic injuries to the iliofemoral vein segment. Dan Med J 59(4):A4410

2. Chase DR, Enzinger FM (1985) Epithelioid sarcoma: diagnosis, prognostic indicators and treatment. Am J Surg Pathol 9(4):241-263 